\title{
Extracorporeal membrane oxygenation in trauma patients: a systematic review
}

\author{
Changtian Wang ${ }^{* \dagger} \mathbb{B}$, Lei Zhang ${ }^{\dagger}$, Tao Qin, Zhilong Xi, Lei Sun, Haiwei Wu and Demin Li
}

\begin{abstract}
Background: Extracorporeal membrane oxygenation (ECMO) has evolved considerably over the past two decades and has been gradually utilized in severe trauma. However, the indications for the use of ECMO in trauma remain uncertain and the clinical outcomes are different. We performed a systematic review to provide an overall estimate of the current performance of ECMO in the treatment of trauma patients.

Materials and methods: We searched PubMed and MEDLINE databases up to the end of December 2019 for studies on ECMO in trauma. The PRISMA statement was followed. Data on demographics of the patient, mechanism of injury, injury severity scores (ISS), details of ECMO strategies, and clinical outcome were extracted.

Results: A total of 58 articles (19 retrospective reports and 39 case reports) were deemed eligible and included. In total, 548 patients received ECMO treatment for severe trauma (adult 517; children 31; mean age of adults $34.9 \pm$ 12.3 years). Blunt trauma (85.4\%) was the primary injury mechanism, and 128 patients had traumatic brain injury (TBI). The mean ISS was $38.1 \pm 15.0$. A total of $71.3 \%$ of patients were initially treated with W ECMO, and $24.5 \%$ were placed on VA ECMO. The median time on ECMO was 9.6 days, and the median time to ECMO was 5.7 days. A total of $60 \%$ of patients received initially heparin anticoagulation. Bleeding (22.9\%) and thrombosis (19\%) were the most common complications. Ischemia of the lower extremities occurred in 9 patients. The overall hospital mortality was $30.3 \%$.
\end{abstract}

Conclusions: ECMO has been gradually utilized in a lifesaving capacity in severe trauma patients, and the feasibility and advantages of this technique are becoming widely accepted. The safety and effectiveness of ECMO in trauma require further study. Several problems with ECMO in trauma, including the role of VA-ECMO, the time to institute $\mathrm{ECMO}$, and the anticoagulation strategy remain controversial and must be solved in future studies.

Keywords: Trauma, Extracorporeal membrane oxygenation (ECMO), Systematic review

\section{Background}

Polytrauma is a leading cause of death among adults [1]. The major causes of early death are hemorrhagic shock, hypoxemia, hypothermia, metabolic acidosis, coagulopathy, and severe traumatic brain injury. Among these causes, hypoxemia or acute respiratory distress syndrome (ARDS) still represents an important and frequent contributing factor toward morbidity and

\section{* Correspondence: wangct35037@163.com}

${ }^{\dagger}$ Changtian Wang and Lei Zhang contributed equally to this work. Department of Cardiovascular Surgery, School Medicine, Jinling Hospital, Nanjing University, Nanjing, People's Republic of China mortality after trauma [2, 3]. A recent systematic review demonstrated no change in the mortality of traumainduced ARDS over the last several decades, and the mortality ranges from 20.6 to $25.8 \%$ [4].

Extracorporeal membrane oxygenation (ECMO) is a simplified version of the heart-lung machine that can restore adequate tissue perfusion and oxygenation, achieve quick rewarming, and infuse massive fluids or blood products. Over the past two decades, ECMO has evolved considerably, especially in ECMO devices (i.e., ECMO devices, centrifugal pump techniques, complete heparincoated circuits, more efficient oxygenators, or device 
miniaturization). Since the first successful use of ECMO in adults for acute posttraumatic respiratory failure reported by Hill et al. in 1972 [5], ECMO has advanced significantly and has become a salvage therapy that may provide an alternative form of management for cardiopulmonary failure in traumatic patients when conventional treatments have failed. However, some concerns remain uncertain in trauma patients, such as the time to ECMO and anticoagulation, and the current clinical outcomes are different. Recently, survival rates for trauma patients undergoing ECMO have been shown to range from $44 \%$ to as high as $74.1 \%$ [6]. The aim of this systematic review is to provide an overall estimate of the current performance of ECMO in the treatment of trauma patients.

\section{Methods}

This systematic review was performed and reported in line with the Preferred Reporting Items for Systematic Reviews and Meta-Analyses (PRISMA) statement [7]. We searched the PubMed and MEDLINE databases up to the end of December 2019 using medical subject headings and text words supplemented by scanning the bibliographies of the recovered articles. We combined "extracorporeal membrane oxygenation", "ECMO", "extracorporeal life support", "ECLS", "extracorporeal cardiopulmonary life support", "trauma", "multitrauma", "polytrauma", and "injury" using the Boolean operator "AND". The results were limited to articles written in English. Two separate researchers (C.W. and L.Z.) analyzed the data set to ensure accuracy and to identify all available studies. The details of each publication were checked to avoid duplicates. Any differences were resolved by consensus.

\section{Inclusion criteria}

All publications, including case reports and case series, reported the application of ECMO during the treatment of trauma patients. Only papers published in English that reported age, sex, mechanism of injury, injury severity score (ISS), details of ECMO, and clinical outcome were included.

\section{Exclusion criteria}

Studies or cases reporting on ECMO for treatment as a bridge for delayed surgery, as support during an emergency operation, on rewarming in the treatment of hypothermia and on burns were not included in this review. Similarly, correspondence, expert opinions, and reviews were excluded. Cases that were not described in the details of demographic data, especially the details of ECMO and outcome, were also not included.

\section{Data extraction and risk of bias assessment}

The following basic parameters were extracted from every publication: first author, date of publication and study, study design (e.g., retrospective study vs. case report), number of patients included, patient demographics, mechanism of injury, type of trauma, ISS, Glasgow coma scale (GCS), details of ECMO (time to ECMO, duration of ECMO, type of ECMO, access route of ECMO), anticoagulation management, mortality, cause of death and ECMO-related complications.

The risk of bias was assessed at the study level using Cochrane's Collaboration Tool [8]. Through six domains, this tool evaluates the risk of bias and categorizes each study as high risk, low risk, or unclear risk.

\section{Statistical analysis}

Data collected were organized on an Apple Numbers (version 6.6.2) spreadsheet. Descriptive statistics were used to describe demographic and continuous data (e.g., mean $\pm \mathrm{SD}$ ). Dichotomous variables are expressed as numbers with percentages.

\section{Results}

The literature search yielded 7624 publications in the PubMed and MEDLINE databases. We screened them by title/abstract and full text. Finally, 58 publications (19 retrospective reports and 39 case reports) that focused on ECMO in trauma were identified from the literature and included in the analysis, spanning a period of time ranging from 1972 to 2019 (Fig. 1). All studies were retrospective studies or case series, with no prospective controlled studies.

\section{Demographic data}

A total of 548 trauma patients requiring ECMO were described, including 517 adults (94.3\%) and 31 children (5.7\%). There was a wide difference in sample size ranging from 1 patient to 85 patients. The retrospective reports had 497 patients, and case reports included 51 patients. The majority of patients were male $(n=441$, $80.1 \%)$, and 99 were female (18.1\%). One report did not provide the patient's gender. In adults, the mean age was $34.9 \pm 12.3$ years (range 18-86 years), and the youngest patient in the group of children was only 21 months old.

Four reports did not provide data on the cause of injury $(n=175)$. In the remaining 373 cases, traffic accidents $(n=254,68.1 \%)$ were the most common cause of injury, followed by falling $(n=38,10.2 \%)$. Gunshots $(n=$ $13,3.5 \%)$ and stabbing $(n=6,1.6 \%)$ were the major causes of penetrating trauma. The data on the mechanism of trauma were available in 53 papers $(n=384)$. Blunt trauma $(n=328,85.4 \%)$ was the primary injury mechanism with very high injury severity and a significant thoracic component. In this review, $259(n=67.4 \%)$ 


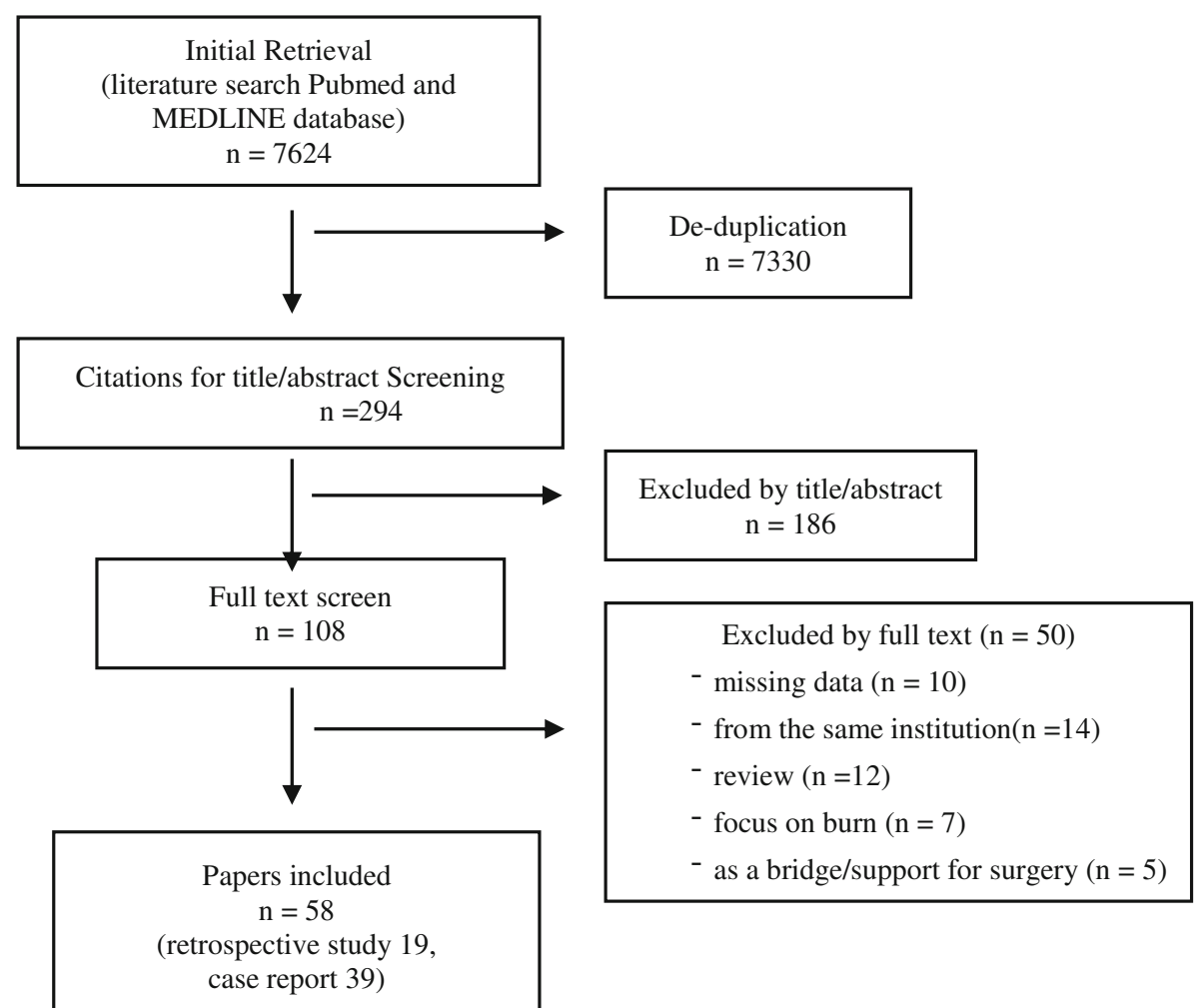

Fig. 1 Flow diagram to illustrate the identification, selection, and exclusion of articles used in the review

patients had chest trauma. Penetration occurred in sixteen patients (4.2\%). A total of 128 patients had traumatic brain injury (TBI) in 52 publications, including 404 trauma patients. Twenty-four papers provided the Injury Severity Score (ISS). The mean ISS was $38.1 \pm$ 15.0 (range 4-75). The mean Glasgow Coma Scale (GCS) was $7.3 \pm 4.7$ (range $3-15$ ) in 19 papers.

The overall hospital mortality was $30.3 \%(n=166)$. There was a wide variation in mortality rates among the studies $(0-71.4 \%)$. In the 19 retrospective reports, the overall mortality was $33 \%(n=164)$, and in case reports, it was $3.9 \%(n=2)$. Six deaths occurred in the pediatric group (19.4\%). The leading cause of death was MOF $(n=34)$. The following causes were sepsis $(n=23)$, cardiorespiratory failure $(n=22)$, cerebrovascular accident $(n=18)$, death after withdrawal of care $(n=11)$, massive hemorrhage $(n=$ $10)$, ECLS failure $(n=4)$, and mesenteric ischemia ( $n$ $=1$ ). The cause of death was unknown or missing among 68 patients (Table 1 ).

\section{ECMO strategies}

A total of 391 patients $(71.3 \%)$ were initially treated with VV ECMO, and 134 patients (24.5\%) were initially placed on VA ECMO. Twelve of those treated with VV ECMO converted to VA ECMO support due to persistent hemodynamic instability. Only two cases on VA ECMO were converted to VV ECMO.

A total of 377 patients $(68.8 \%)$ were cannulated peripherally, three patients were centrally cannulated (femoral vein-aortic root; right atrium-aorta; right atriumpulmonary artery), and 168 patients (30.7\%) did not describe the type of cannulation. Single dual-lumen catheters were used in this group, but the details could not be identified from the literature.

The median time on ECMO was 9.6 days in this group, and the longest was 114 days. The duration before ECMO support was recorded differently, including from injury to ECMO, from ER to ECMO, from the onset of ARDS to ECMO, and from the ventilator to ECMO. The median time before ECMO support was 5.7 days. In 28 cases, this time was recorded approximately $(<1$ day $)$ (Table 2).

\section{Anticoagulation}

The anticoagulation strategy on ECMO in trauma patients differed among institutions. Seven papers included 164 cases $(30 \%)$ that did not provide details of anticoagulation. A total of 329 patients (60\%) received anticoagulation while on ECMO, and 55 patients did not receive anticoagulation. In the anticoagulation group, $135(24.6 \%)$ patients received heparin systemic 


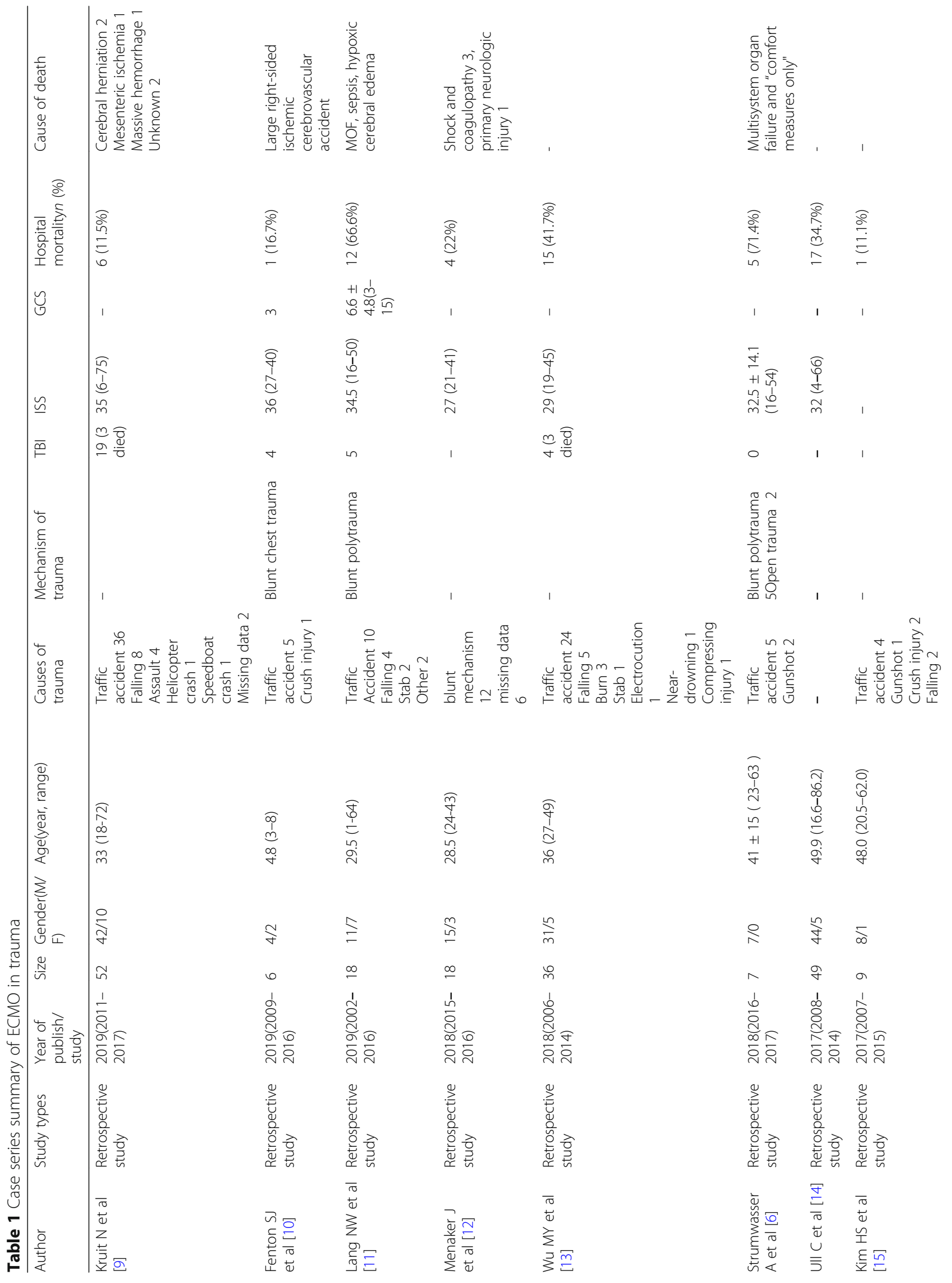




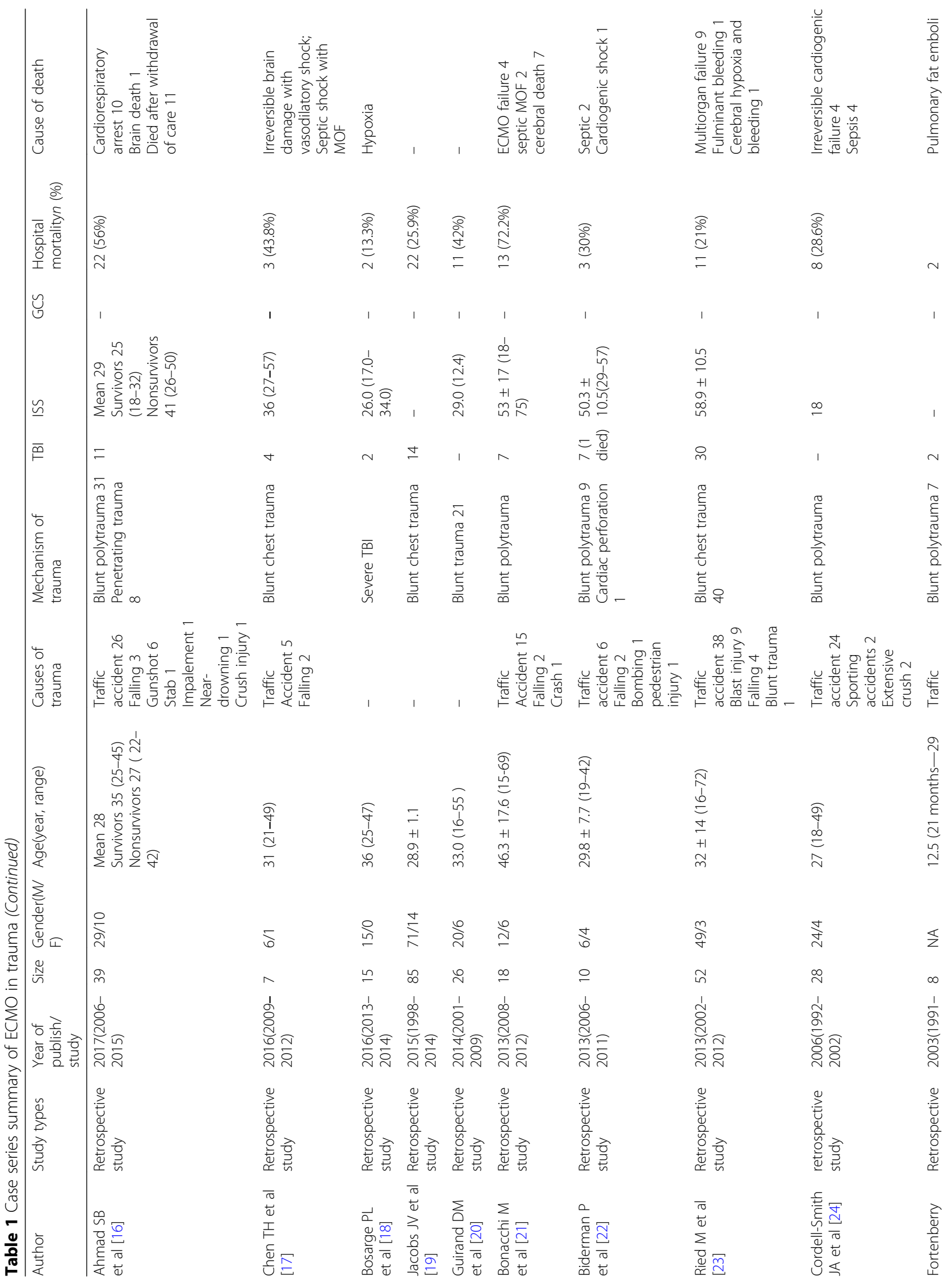




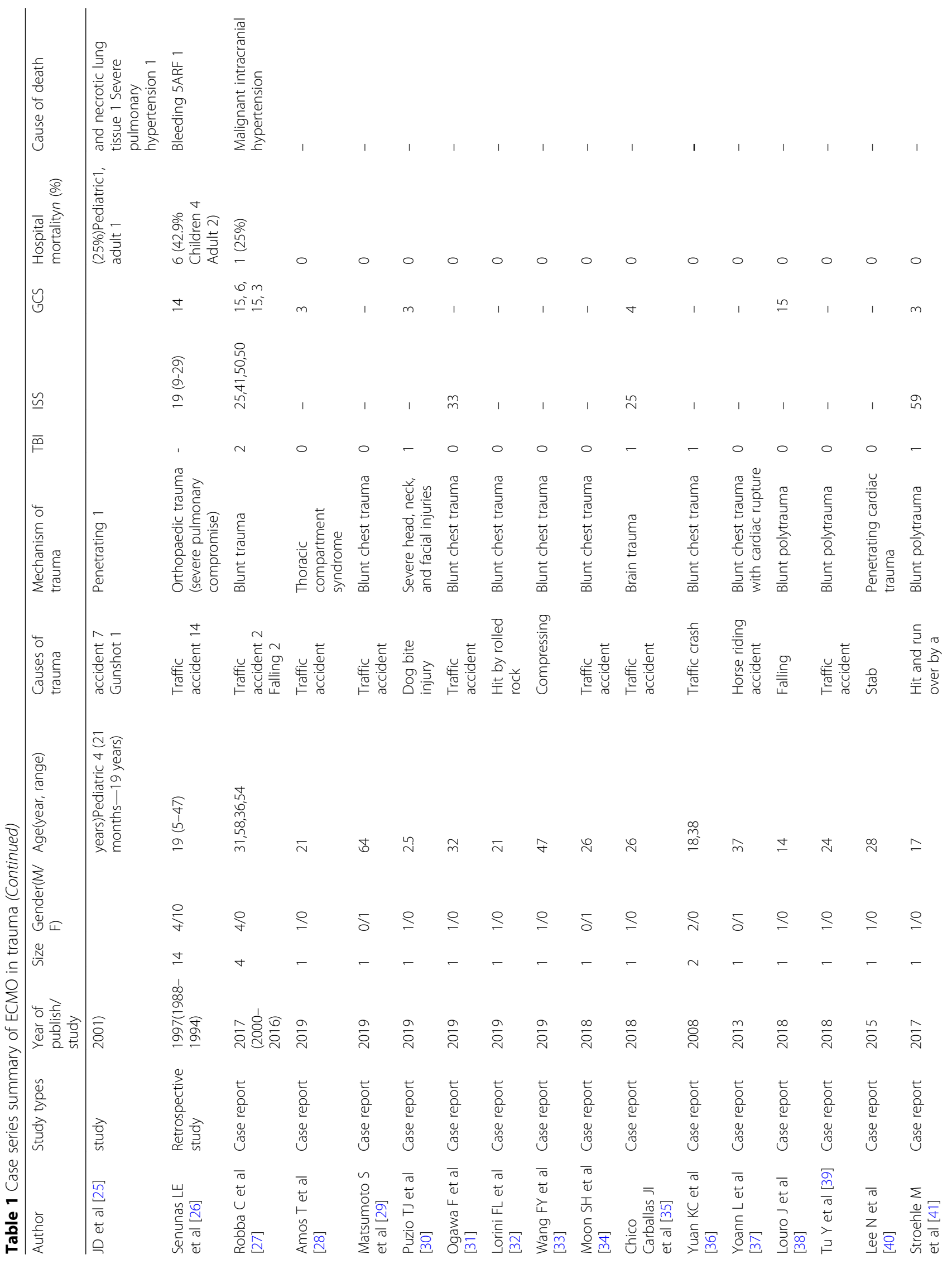




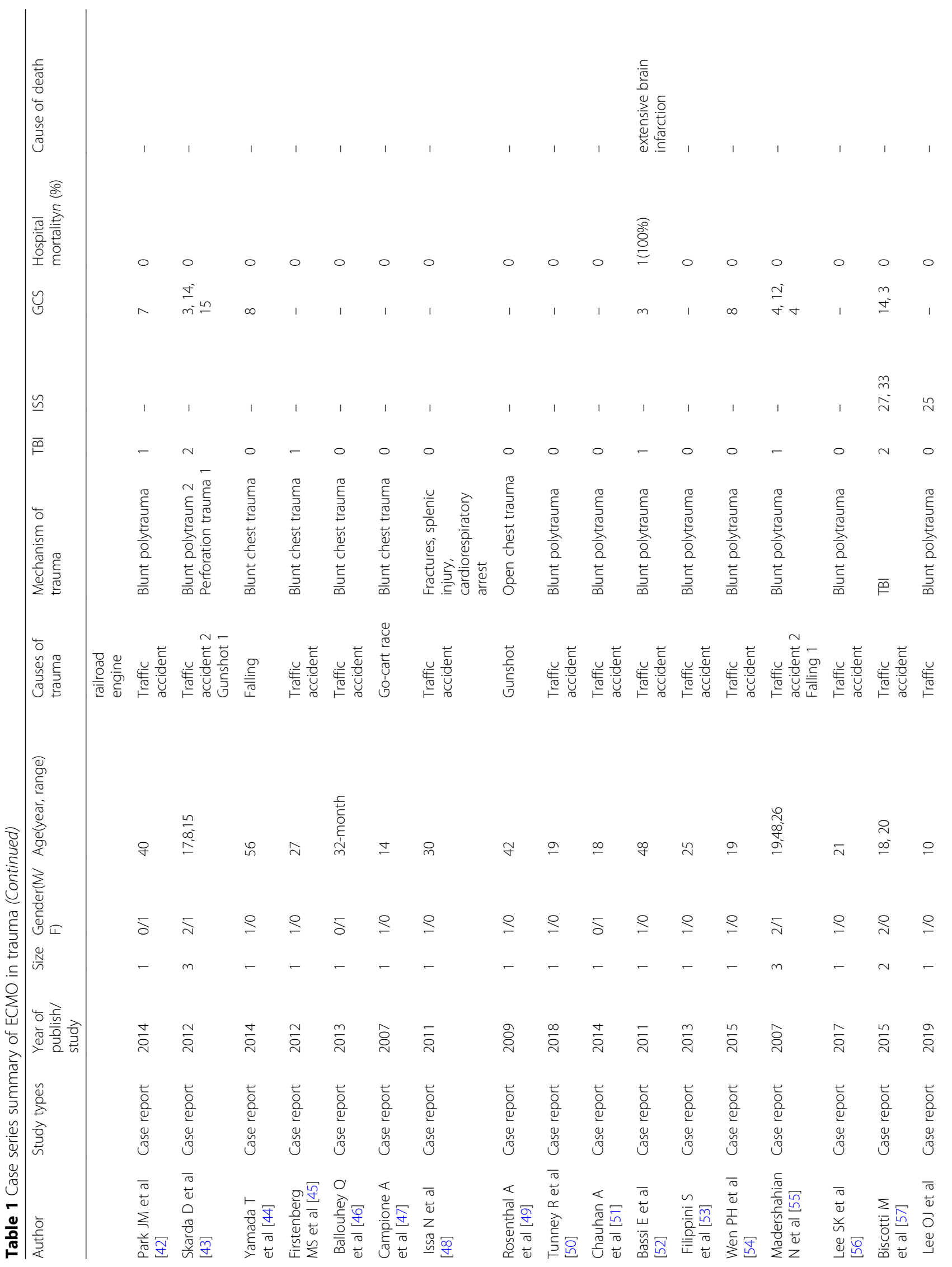




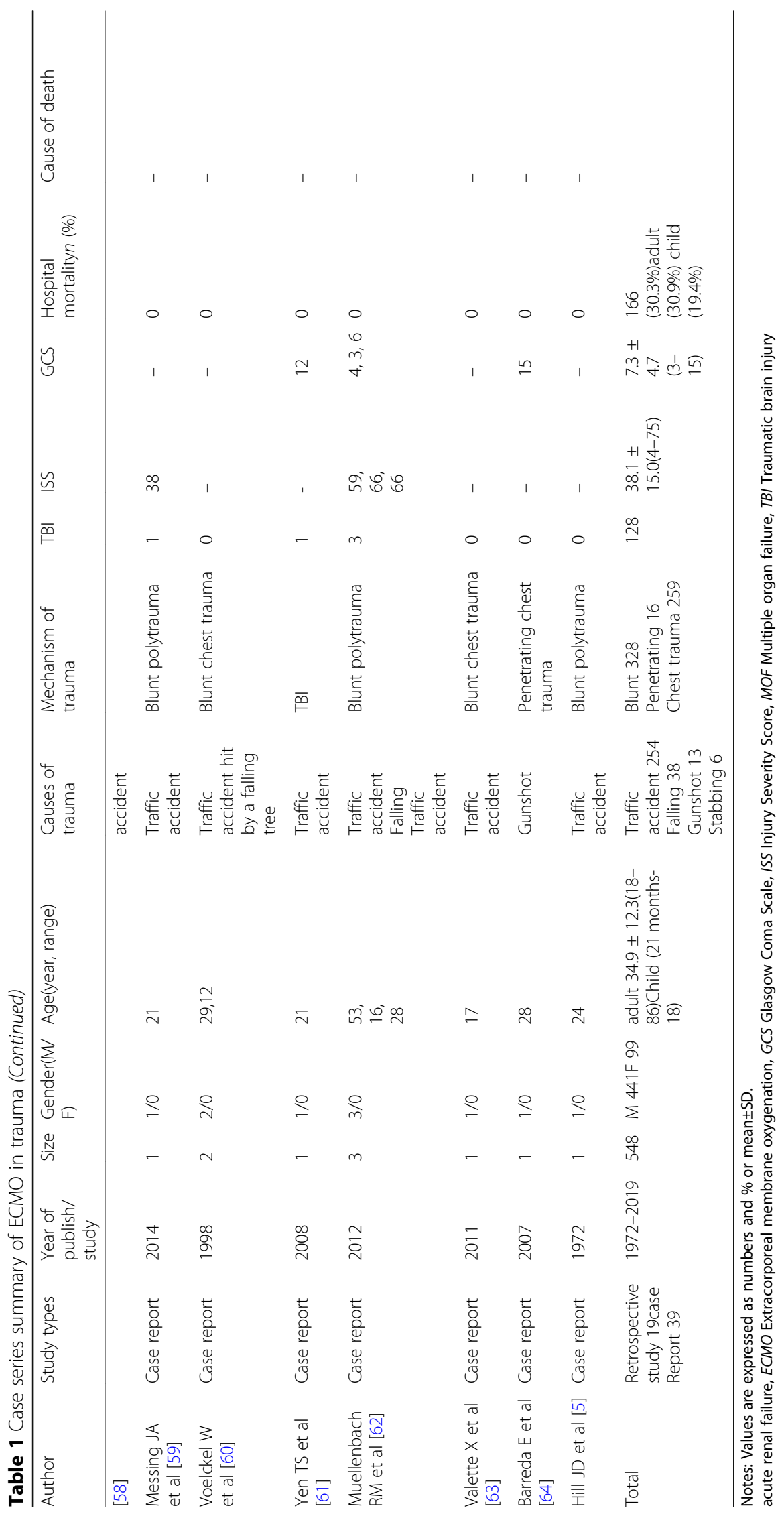


Table 2 The details of ECMO support

\begin{tabular}{ll}
\hline ECMO support & $\begin{array}{l}\text { Size } \\
(\boldsymbol{n}, \%)\end{array}$ \\
\hline W-ECMO-no. (\%) & $391(71.4)$ \\
VA-ECMO-no. (\%) & $134(24.5)$ \\
W convert to VA—no. (\%) & $12(2.2)$ \\
VA convert to W-no. (\%) & $2(0.4)$ \\
missing type-no. (\%) & $23(4.2)$ \\
PC-mode-no. (\%) & $377(68.8)$ \\
CC-mode-no. (\%) & $3(0.5)$ \\
Missing mode-no. (\%) & $168(30.7)$ \\
Duration of ECMO (days, mean) & 9.6 \\
Time to ECMO (days, mean) & $5.7^{\mathrm{a}}$ \\
\hline
\end{tabular}

Notes: Values are expressed as numbers and \% or mean \pm SD. CC Central cannulation, ECMO Extracorporeal membrane oxygenation, $P C$ Peripheral cannulation, VA-ECMO Veno-arterial extracorporeal membrane oxygenation, $V$-ECMO Veno-venous extracorporeal membrane oxygenation ${ }^{a}$ The record of time to ECMO was different in publications, including from ER to ECMO, from the onset of ARDS to ECMO, from the ventilator to ECMO

anticoagulation. Heparin titration (heparin-minimized strategy) was applied to $80(14.6 \%)$ patients. A total of $101(18.4 \%)$ patients were initially managed with heparin (did not provide the later strategy), while $13(2.4 \%)$ patients were initially managed with heparin (1-3 days); then, heparin was stopped due to bleeding or other causes. In the anticoagulation-free group, $16(2.9 \%)$ patients did not receive any anticoagulation while on ECMO. Initial heparin-free therapy occurred in 14 (2.6\%) patients, and $24(4.4 \%)$ patients received initial heparin-free therapy ( $2.5 \mathrm{~h}-5$ days) followed by heparin systemic anticoagulation. Nafamostat mesilate was reported on ECMO in two studies, but the details could not be extracted.

Activated clotting time (ACT) and activated partial thromboplastin time (aPTT) were the two most common coagulation parameters, which were used in 124 cases and 120 cases, respectively. ACT between 180 and $220 \mathrm{~s}$ was the most targeted time. The target aPTT was between 40 and $80 \mathrm{~s}$. In one study, the target was a TEG-reactive (R) time of two times the nonheparinized baseline.

\section{Complications}

A total of 104 patients $(22.9 \%)$ had documented bleeding complications at 120 sites, including surgical site bleeding $(n=26)$, cannula site bleeding $(n=20)$, diffuse bleeding or DIC $(n=12)$, intracranial bleeding $(n=7)$, intrathoracic bleeding $(n=5)$, intra-abdominal bleeding $(n=3)$, gastrointestinal bleeding $(n=5)$, pulmonary bleeding $(n=3)$, bleeding from tracheostomies $(n=2)$, and bleeding from the mouth or nose $(n=2)$. Thirtyfive sites were missing (Fig. 2). Four papers, which included 94 patients, did not report bleeding complications. The surgical site was the most common bleeding site, followed by the cannula site. The incidence of bleeding complications was different in series reports, ranging from 0 to $87.5 \%$, and the majority of these events did not require surgical intervention.

Notes:

$\mathrm{MS}=$ missing site $; \mathrm{SS}=$ surgical site $; \mathrm{CS}=$ cannula site DD = diffuse bleeding or

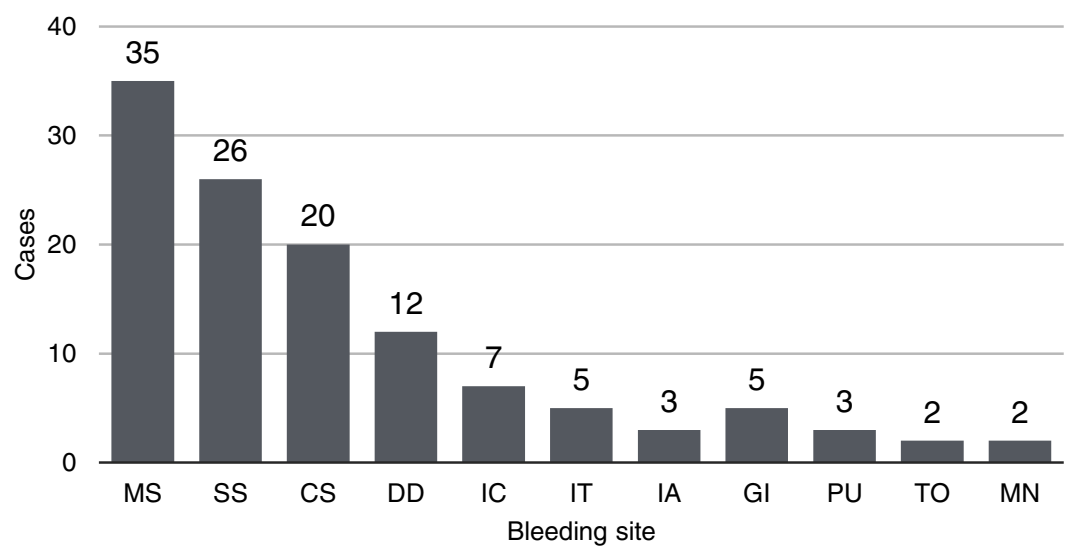

DIC; IC = intracranial; IT = intra-thoracic; IA = intra- abdominal; GI = gastrointesti-

nal; $\mathrm{PU}=$ pulmonary; $\mathrm{TO}=$ tracheostomies $; \mathrm{MN}=$ mouth or nose

Fig. 2 The summary of documented bleeding complication during ECMO in trauma. Notes: $M S=$ missing site; $S S=$ surgical site; $C S=$ cannula site; $\mathrm{DD}=$ diffuse bleeding or $\mathrm{DIC} ; \mathrm{IC}=$ intracranial; $I T$ = intra-thoracic; $I \mathrm{~A}=$ intra- abdominal; $\mathrm{Gl}$ = gastrointestinal; $\mathrm{PU}=$ pulmonary; $\mathrm{TO}=$ tracheostomies; $\mathrm{MN}=$ mouth or nose 
Note:

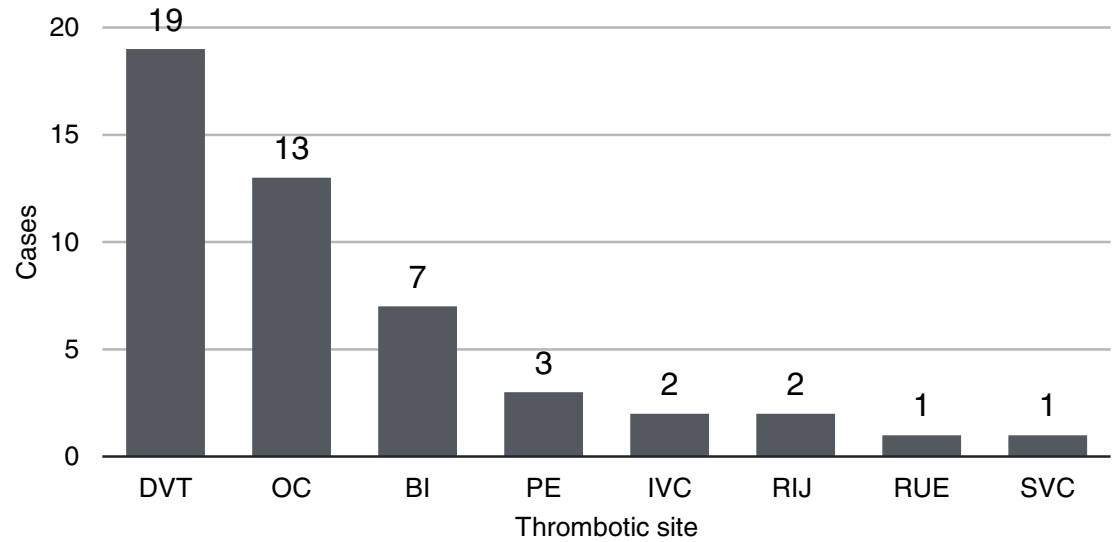

$\mathrm{DVT}=$ femoral deep venous thrombosis; $\mathrm{OC}=$ oxygenator and circuit $\mathrm{BI}=$ brain in-

farction; $\mathrm{PE}=$ pulmonary embolism; RUE = right upper extremity; $\mathrm{SVC}=$ superior

vena cava; IVC = inferior vena cava; RIJ = right internal jugular vein.

Fig. 3 The summary of documented thrombotic complication during ECMO in trauma. Notes: DVT = femoral deep venous thrombosis; OC = oxygenator and circuit; $\mathrm{BI}$ = brain infarction; $\mathrm{PE}$ = pulmonary embolism; RUE = right upper extremity; SVC = superior vena cava; IVC = inferior vena cava; RIJ = right internal jugular vein

Thrombotic complications are listed in Fig. 3, including femoral deep venous thrombosis (DVT), oxygenator and circuit clotting, brain infarction, pulmonary embolism, inferior vena cava (IVC) thrombus, right internal jugular vein (RIJ) thrombus, right upper extremity (RUE) thrombus, and superior vena cava (SVC) thrombus. Nine papers (296 cases) did not document complications. Forty-eight of 252 patients (19\%) experienced thrombotic complications. A total of $39.6 \%$ of patients had femoral DVT. The incidence of thrombi in oxygenators and circuits was $27.1 \%$.

The other ECMO-related complications occurred in 25 cases reported in 15 publications, including ischemia of the lower extremity, abdominal compartment syndrome, brain swelling, acute lung edema, acute pancreatitis, accidental removal of a cannula, pseudoaneurysm developed on the site of the cannula, and secondary sclerosing cholangitis in critically ill patients (SSC-CIP) (Table 3). Ischemia of the lower extremities $(n=9)$ was the most common cannula-related complication, and 3 patients underwent fasciotomy. The other complications were very rare.

\section{Discussion}

Generally, the lung is the first organ to fail after severe trauma (failure after $3.7 \pm 2.8$ days) [65]. In our review, ECMO has been used successfully in a series of trauma patients, but the evidence of benefit is still limited. From our investigation, the reported mortality in publications ranged from 11.1 to $71.4 \%$, with the exception of case reports. The mean hospital mortality was $30.3 \%$, while in the pediatric group, it was $19.4 \%$. Mortality remains high, and the cause should take into account the overall injury as well as those that are ECMO-related, because most of the population in this study was young and had a median age of 34.9 years, with good cardiopulmonary function at baseline. In a multicenter study by Kruit et al. [9], fifty-two patients who experienced trauma and were supported with ECMO were identified from the five ECMO centers. The overall hospital mortality was $11.5 \%$, and the overall 180 -day mortality was $15 \%$. These

Table 3 The summary of other ECMO-related complications in trauma

\begin{tabular}{ll}
\hline Complications & Size \\
\hline Ischemia of lower extremity (fasciotomy 3) & 9 \\
Abdominal compartment syndrome & 2 \\
Brain swelling & 2 \\
Acute lung edema & 1 \\
Acute pancreatitis & 1 \\
Accidental removal of a cannula & 1 \\
Pseudoaneurysm developed on the site of cannula & 1 \\
SSC-CIP & 1 \\
Non-record & 7 \\
Total & 25 \\
\hline
\end{tabular}

Notes: ECMO Extracorporeal membrane oxygenation, SSC-CIP Secondary sclerosing cholangitis in critically ill patients 
preliminary results suggest that ECMO may provide survival benefits and seems to be safe in selected trauma populations. However, owing to the difference of injury, indications and time of ECMO, and follow-up data, the benefits of ECMO in trauma should be confirmed through further studies, for example, randomized control trials.

When to initiate ECMO is a challenge to clinicians. In this study, the time to initiate ECMO in the trauma patients was different, ranging from 0 to 24 days, and the mean time was 5.7 days. Kruit et al. demonstrated that there was no significant difference between survivors and nonsurvivors in time from injury to ECMO commencement [9]. Ahmad et al. [16] also did not find an association between the time to initiation of ECMO and mortality. Summary data suggest that delaying the institution of ECMO may cause irreversible pulmonary and cardiac injuries in addition to other organs and lead to poor outcomes [66]. Bosarge et al. evaluated a series of 15 patients with severe ARDS who underwent early ECMO (mean 1.9 days) and found that the patients in the early ECMO group had improved survival (64\%) compared with historical controls (13\%), suggesting that ECMO should be considered at the early onset of severe ARDS to improve survival [18]. Early ECMO initiation may offer advantages such as reducing ventilator time to prevent iatrogenic lung damage from highpressure and high $\mathrm{FiO} 2$ ventilation, supplying adequate oxygenation and/or tissue perfusion, and providing lung and heart rest. However, ECMO initiation may increase the bleeding risk in the early stages of trauma due to heparin systemic anticoagulation, especially in patients with intracranial or active systemic bleeding.

VV ECMO with peripheral cannulation (PC) is the most common model of ECMO in trauma. In this review, $71.4 \%$ of patients received VV ECMO support, and $24.5 \%$ received VA ECMO. The study based on the ELSO registry [19] showed a trend toward the use of venovenous ECMO compared with venoarterial ECMO, as $79.4 \%$ of survivors were treated with venovenous ECMO compared with $59.1 \%$ of nonsurvivors. One recent systematic review combining 215 trauma patients supported with ECMO reported a survival-to-discharge rate ranging from 56 to $89 \%$ after VV ECMO and 42 to $63 \%$ after VA ECMO [3]. In the study reported by Lang et al. [11], VA ECMO was applied in 15 cases, and 11 patients (73\%) died. However, limited studies have examined outcomes for VA ECMO in trauma patients. VA ECMO is indicated for cardiopulmonary support rather than for pulmonary support alone, which enables the restricted and congested heart to recover by unloading the heart. Severe chest trauma in many cases can cause acute lethal cardiac failure primarily by contusion of the heart or secondary by pulmonary contusion. These patients might benefit from ECMO. A recent study [13] using ECMO to treat patients with advanced shock or respiratory failure showed different mortality rates between VA and VV ECMO: 64.3\% in VA ECMO and $27.3 \%$ in VV ECMO. It is likely that patients requiring VA ECMO had poorer survival rates because they required hemodynamic support and not simply because VA ECMO was used. Therefore, much work still needs to be done to determine the effects and safety of VA ECMO in severe trauma patients.

Therapeutic heparin potentially increases the risk of bleeding, especially in polytrauma with TBI and/or intracranial bleeding. In this review, there are different anticoagulation strategies in the literature, including full heparin systemic anticoagulation, a heparin-minimized strategy, and all heparin-free, initially heparin-free and delayed heparin-free treatments, and there was a wide range (1.9-87.5\%) of reported bleeding complications. According to the Extracorporeal Life Support Organization Registry Report 2012 [67], the main complication during VV-ECMO is bleeding, which occurs in 17 to $21.3 \%$ of cases. In the report by Ahmad et al [16], the use of anticoagulation was significantly associated with survival: $94 \%$ of survivors were anticoagulated versus only $55 \%$ of nonsurvivors. However, several reports have shown that patients can be successfully managed on heparin-free ECMO without increasing the extent of the bleeding $[17,22,28,29,35,38]$. These may benefit from the technological advancements in ECMO, including the use of more efficient membrane oxygenators, centrifugal pumps, miniaturization of circuits, and heparin-bonded circuitry, which have allowed ECMO use with little or no anticoagulation. Anticoagulation should be individually tailored, taking into account the severity of the trauma, the timing, and active bleeding.

In this literature review, 128 patients suffering from traumatic brain injury (TBI) were included. Unfortunately, the details of anticoagulation and mortality could not be identified. Biderman et al. [22] reported a series of 10 patients, including 7 with TBI and six patients who survived. The median GCS score on arrival was 7 (range 5-9) and improved in all survivors to 14 (range 12-15). All but two patients regained normal neurologic status during follow-up. Of the 10 patients, only 3 could receive heparin during the first $48 \mathrm{~h}$. In those patients who could not receive heparin, high blood flow $(4-5 \mathrm{~L} / \mathrm{min})$ was maintained to prevent clotting. In a multicenter study [9], 52 traumatic patients were included, and 19 had TBI. Twelve patients with TBI (63\%) were anticoagulated, and 3 with TBI died (16\%). In another series report [17] including 7 consecutive severe trauma patients and 4 with 
TBI, VV-ECLS was not withheld from patients with TBI despite evidence of intracranial bleeding. Four patients were successfully discharged, and three of these survivors had concomitant TBI without neurologic sequelae. TBI is not contraindicated for ECMO, and routine management, including mild hypothermia $\left(34^{\circ} \mathrm{C}\right)$, can be tolerated under heparin-free VV ECMO [17, 68]. The current findings do not support neurological injury as an absolute contraindication to ECMO.

\section{Limitations}

This systematic review presents limitations. All of the included publications on ECMO technology in trauma still consist of either retrospective studies or case series with limited data or case reports, and thus, the present report possesses all the inherent limitations, including the weak of the evidence, geographical bias, publication bias, search bias, methodology bias. Another limitation is the number and quality of the studies available for qualitative analysis. Some studies had incomplete data. Finally, follow-up data and long-term survival data are not yet available from this analysis. Therefore, a general conclusion from a solid statistical analysis with adequate samples is lacking.

\section{Conclusions}

Our systematic review illustrates that ECMO has been gradually utilized in a lifesaving capacity in patients with severe trauma, and the feasibility and advantages of this technique are becoming widely accepted. However, the safety and effectiveness of ECMO in trauma require further study. Several problems with ECMO in trauma, including the role of VA-ECMO, the time to institute $\mathrm{ECMO}$, and the anticoagulation strategy remain controversial and must be solved in the future studies. Indeed, clinical randomized control trials with large samples and long-term survival data are needed.

\section{Abbreviations}

ACT: Activated clotting time; ARDS: Acute respiratory distress syndrome; aPTT: Activated partial thromboplastin time; DIC: Disseminated intravascular coagulation; DVT: Deep venous thrombosis; ECLS: Extracorporeal cardiopulmonary life support; ECMO: Extracorporeal membrane oxygenation; GCS: Glasgow coma scale; ISS: Injury severity scores; IVC: Inferior vena cava; MOF: Multiple organ failure; PRISMA: The preferred reporting items for systematic reviews and meta-analyses; RIJ: Right internal jugular vein; RUE: Right upper extremity; SVC: Superior vena cava; TBI: Traumatic brain injury; thrombus; VA-ECMO: Veno-arterial extracorporeal membrane oxygenation; W-ECMO: Veno-venous extracorporeal membrane oxygenation

\section{Authors' contributions}

CW contributed to conceptualization, data curation, formal analysis, methodology, validation, writing-review, and editing; LZ contributed to data curation, investigation, methodology; TQ contributed to data curation, investigation, and methodology; ZX contributed to data curation and investigation; LS contributed to data curation and investigation; HW contributed to data curation and investigation; DL contributed to supervision, validation, and review. All authors read and approved the final manuscript.

\section{Funding}

This research received no specific grant from any funding agency in the public, commercial, or not-for-profit sectors.

\section{Availability of data and materials}

All data generated or analyzed during this study are included in this published article [and its supplementary information files].

\section{Ethics approval and consent to participate}

Not applicable, systematic review.

\section{Consent for publication}

Not applicable, systematic review.

\section{Competing interests}

The authors declare that they have no competing interests.

Received: 20 July 2020 Accepted: 23 August 2020

Published online: 11 September 2020

\section{References}

1. Rhee P, Joseph B, Pandit V, Aziz H, Vercruysse G, Kulvatunyou N, et al. Increasing trauma deaths in the United States. Ann Surg. 2014;260:13-21. https://doi.org/10.1097/SLA.0000000000000600.

2. Daurat A, Millet I, Roustan JP, Maury C, Taourel P, Jaber S, Capdevila X Charbit J. Thoracic trauma severity score on admission allows to determine the risk of delayed ARDS in trauma patients with pulmonary contusion. Injury. 2016;47(1):147-53. https://doi.org/10.1016/j.injury.2015.08.031.

3. Bedeir K, Seethala R, Kelly E. Extracorporeal life support in trauma: Worth the risks? A systematic review of published series. J Trauma Acute Care Surg. 2017;82(2):400-6. https://doi.org/10.1097/TA.0000000000001292.

4. Birkner DR, Halvachizadeh S, Pape HC, Pfeifer R. Mortality of adult respiratory distress syndrome in trauma patients: a systematic review over a period of four decades. World J Surg. 2020;16. https://doi.org/10.1007/s00268-02005483-5.

5. Hill JD, O'Brien TG, Murray JJ, Dontigny L, Bramson ML, Osborn JJ, Gerbode F. Prolonged extracorporeal oxygenation for acute post-traumatic respiratory failure (shock-lung syndrome). Use of the Bramson membrane lung. N Engl J Med. 1972;286(12):629-34. https://doi.org/10.1056/ NEJM197203232861204.

6. Strumwasser A, Tobin JM, Henry R, Guidry C, Park C, Inaba K, Demetriades D. Extracorporeal membrane oxygenation in trauma: a single institution experience and review of the literature. Int J Artif Organs. 2018;41(12):84553. https://doi.org/10.1177/0391398818794111

7. Liberati A, Altman DG, Tetzlaff J, et al. The PRISMA statement for reporting systematic reviews and meta-analyses of studies that evaluate health care interventions: explanation and elaboration. J Clin Epidemiol. 2009;62(10):e1e34. https://doi.org/10.1016/j.jclinepi.2009.06.006

8. Higgins JP, Altman DG, Gøtzsche PC, Jüni P, Moher D, Oxman AD, Savovic J, Schulz KF, Weeks L, Sterne JA, Cochrane Bias Methods Group; Cochrane Statistical Methods Group. The cochrane collaboration's tool for assessing risk of bias in randomised trials. BMJ. 2011;343:d5928. https://doi.org/10. 1136/bmj.d5928.

9. Kruit N, Prusak M, Miller M, Barrett N, Richardson C, Vuylsteke A. Assessment of safety and bleeding risk in the use of ECMO for multi-trauma patients: a multicentre review. J Trauma Acute Care Surg. 2019;86(6):967-73. https:// doi.org/10.1097/TA.0000000000002242.

10. Fenton SJ, Hunt MM, Ropski PS, Scaife ER, Russell KW. Use of ECMO support in pediatric patients with severe thoracic trauma. J Pediatr Surg. 2019;54(11): 2358-62. https://doi.org/10.1016/j.jpedsurg.2019.02.018.

11. Lang NW, Schwihla I, Weihs V, Kasparek M, Joestl J, Hajdu S, Sarahrudi K. Survival rate and Outcome of extracorporeal life support (ECLS) for treatment of acute cardiorespiratory failure in trauma patients. Sci Rep. 2019;9(1):12902. https://doi.org/10.1038/s41598-019-49346-z.

12. Menaker J, Tesoriero RB, Tabatabai A, Rabinowitz RP, Cornachione C, Lonergan T, Dolly K, Rector R, O'Connor JV, Stein DM, Scalea TM. Venovenous extracorporeal membrane oxygenation (W ECMO) for Acute respiratory failure following injury: outcomes in a high-volume adult trauma center with a dedicated unit for W ECMO. World J Surg. 2018;42(8):2398403. https://doi.org/10.1007/s00268-018-4480-6. 
13. Wu MY, Chou PL, Wu TI, Lin PJ. Predictors of hospital mortality in adult trauma patients receiving extracorporeal membrane oxygenation for advanced life support: a retrospective cohort study. Scand J Trauma Resusc Emerg Med. 2018;26(1):14. https://doi.org/10.1186/s13049-018-0481-6.

14. UII C, Schildhauer TA, Strauch JT, Swol J. Outcome measures of extracorporeal life support (ECLS) in trauma patients versus patients without trauma: a 7-year single-center retrospective cohort study. J Artif Organs. 2017;20(2):117-24. https://doi.org/10.1007/s10047-016-0938-1.

15. Kim HS, Ha SO, Han SJ, Kim HS, Lee SH, Jung KS, Park S. Extracorporeal Membrane Oxygenation Support In Trauma Versus Nontrauma Patients With Noninfectious Acute Respiratory Failure. Artif Organs. 2017;41(5):431-9. https://doi.org/10.1111/aor.12794.

16. Ahmad SB, Menaker J, Kufera J, O'Connor J, Scalea TM, Stein DM. Extracorporeal membrane oxygenation after traumatic injury. J Trauma Acute Care Surg. 2017;82(3):587-91. https://doi.org/10.1097/TA. 0000000000001352.

17. Chen TH, Shih JY, Shih JJ. Early percutaneous heparin-free veno-venous extra corporeal life support (ECLS) is a safe and effective means of salvaging hypoxemic patients with complicated chest trauma. Acta Cardiol Sin. 2016; 32(1):96-102.

18. Bosarge PL, Raff LA, McGwin G Jr, Carroll SL, Bellot SC, Diaz-Guzman E, Kerby JD. Early initiation of extracorporeal membrane oxygenation improves survival in adult trauma patients with severe adult respiratory distress syndrome. J Trauma Acute Care Surg. 2016;81(2):236-43. https://doi.org/10. 1097/TA.0000000000001068.

19. Jacobs JV, Hooft NM, Robinson BR, Todd E, Bremner RM, Petersen SR, Smith $M A$. The use of extracorporeal membrane oxygenation in blunt thoracic trauma: A study of the Extracorporeal Life Support Organization database. J Trauma Acute Care Surg. 2015;79(6):1049-53. https://doi.org/10.1097/TA. 0000000000000790

20. Guirand DM, Okoye OT, Schmidt BS, Mansfield NJ, Aden JK, Martin RS, Cestero RF, Hines MH, Pranikoff T, Inaba K, Cannon JW. Venovenous extracorporeal life support improves survival in adult trauma patients with acute hypoxemic respiratory failure: a multicenter retrospective cohort study. J Trauma Acute Care Surg. 2014;76(5):1275-81. https://doi.org/10. 1097/TA.0000000000000213.

21. Bonacchi M, Spina R, Torracchi L, Harmelin G, Sani G, Peris A. Extracorporeal life support in patients with severe trauma: an advanced treatment strategy for refractory clinical settings. J Thorac Cardiovasc Surg. 2013;145(6):161726. https://doi.org/10.1016/j.jtcvs.2012.08.046.

22. Biderman $P$, Einav $S$, Fainblut $M$, Stein $M$, Singer $P$, Medalion $B$. Extracorporeal life support in patients with multiple injuries and severe respiratory failure: a single-center experience? J Trauma Acute Care Surg. 2013;75(5):907-12. https://doi.org/10.1097/TA.0b013e3182a8334f.

23. Ried M, Bein T, Philipp A, Müller T, Graf B, Schmid C, Zonies D, Diez C, Hofmann HS. Extracorporeal lung support in trauma patients with severe chest injury and acute lung failure: a 10-year institutional experience. Crit Care. 2013;17(3):R110. https://doi.org/10.1186/cc12782.

24. Cordell-Smith JA, Roberts N, Peek GJ, Firmin RK. Traumatic lung injury treated by extracorporeal membrane oxygenation (ECMO). Injury. 2006;37(1): 29-32. https://doi.org/10.1016/j.injury.2005.03.027.

25. Fortenberry JD, Meier AH, Pettignano R, Heard M, Chambliss CR, Wulkan M. Extracorporeal life support for posttraumatic acute respiratory distress syndrome at a children's medical center. J Pediatr Surg. 2003;38(8):1221-6. https://doi.org/10.1016/s0022-3468(03)00272-0.

26. Senunas LE, Goulet JA, Greenfield ML, Bartlett RH. Extracorporeal life support for patients with significant orthopaedic trauma. Clin Orthop Relat Res. 1997:339:32-40. https://doi.org/10.1097/00003086-199706000-00005.

27. Robba C, Ortu A, Bilotta F, Lombardo A, Sekhon MS, Gallo F, Matta BF. Extracorporeal membrane oxygenation for adult respiratory distress syndrome in trauma patients: A case series and systematic literature review. J Trauma Acute Care Surg. 2017;82(1):165-73. https://doi.org/10.1097/TA 0000000000001276.

28. Amos T, Yeung M, Gooi J, Fitzgerald M. Survival following traumatic thoracic compartment syndrome managed with W-ECMO. Trauma Case Rep. 2019; 24:100249. https://doi.org/10.1016/j.tcr.2019.100249.

29. Matsumoto S, Morizane M, Matsuo K, Yamazaki M, Kitano M. Pitfalls when using extracorporeal life support in trauma patients. Trauma Surg Acute Care Open. 2019;4(1):e000298. https://doi.org/10.1136/tsaco-2019-000298.

30. Puzio TJ, Cools K, Adamson W, Erickson K. Venoarterial extracorporeal life support utilization in a Pediatric trauma patient following a severe dog mauling. Pediatr Emerg Care. 2019. https://doi.org/10.1097/PEC. 0000000000001753.

31. Ogawa F, Sakai T, Takahashi K, Kato M, Yamaguchi K, Okazaki S, Abe T, Iwashita M, Takeuchi I. A case report: veno-venous extracorporeal membrane oxygenation for severe blunt thoracic trauma. J Cardiothorac Surg. 2019;14(1):88. https://doi.org/10.1186/s13019-019-0908-9.

32. Lorini FL, Grazioli L, Manfredi R, Rausa E, Ghitti D, Poli G, Peck M, Cattaneo S. A prolonged and successful heparin-free extracorporeal membrane oxygenation run in isolated thoracic trauma: A case report. Int J Artif Organs. 2019;391398819887400. https://doi.org/10.1177/ 0391398819887400 .

33. Wang FY, Fang B, Yu ZH, Shao JS, Wen WB, Zhou LX. Severe thoracic trauma caused left pneumonectomy complicated by right traumatic wet lung, reversed by extracorporeal membrane oxygenation support-a case report. BMC Pulm Med. 2019;19(1):30. https://doi.org/10.1186/s12890-0190790-1.

34. Moon SH, Kim KN, Jung JJ, Park JH, Byun JH. Heparin-free veno-venous ECMO applied to a patient with severe lung contusion and hypovolemic shock due to trauma. Ulus Travma Acil Cerrahi Derg. 2018:24(5):497-500. https://doi.org/10.5505/tjtes.2018.33802.

35. Chico Carballas JI, Freita Ramos S, Mosquera Rodriguez D, Menor Fernandez EM, Piñon Esteban M, Casais PR. ECMO in severe trauma patient with intracranial bleeding requiring surgery. Med Intensiva. 2018. pii: S02105691(18)30285-7; 10.1016/..medin.2018.10.002.

36. Yuan KC, Fang JF, Chen MF. Treatment of endobronchial hemorrhage after blunt chest trauma with extracorporeal membrane oxygenation (ECMO). J Trauma. 2008;65(5):1151-4. https://doi.org/10.1097/01.ta. 0000235492.09223 .83$.

37. Yoann L, Erwan F, Nicolas N, Yannick M, Philippe S. Extracorporeal life support in a severe blunt chest trauma with cardiac rupture. Case Rep Crit Care. 2013;2013:136542. https://doi.org/10.1155/2013/136542.

38. Louro J, Weir JJ, Brozzi NA, Dudaryk R. Treatment of refractory intraoperative hypoxemia after trauma with venovenous extracorporeal membrane oxygenation: A Case Report. A A Pract. 2018;11(2):41-5. https://doi.org/10. 1213/XAA.0000000000000731.

39. Tu Y, Jin Q, Sun R, Li Q. Extracorporeal membrane oxygenation support for a multitrauma patient with ARDS: A case report and literature review. Exp Ther Med. 2018;15(2):2062-5. https://doi.org/10.3892/etm.2017.5604.

40. Lee $\mathrm{N}$, Tang D, Jayaraman S. Penetrating cardiac trauma and the use of emergent extracorporeal membrane oxygenation and therapeutic hypothermia: When cooler heads prevail. Trauma Case Rep. 2015;1(9-12):958. https://doi.org/10.1016/j.tcr.2015.10.011

41. Stroehle M, Lederer W, Schmid S, Glodny B, Chemelli AP, Wiedermann FJ. Aortic stent graft placement under extracorporeal membrane oxygenation in severe multiple trauma. Clin Case Rep. 2017;5(10):1604-7. https://doi.org/ 10.1002/ccr3.1127

42. Park JM, Kim CW, Cho HM, Son BS, Kim DH. Induced airway obstruction under extracorporeal membrane oxygenation during treatment of lifethreatening massive hemoptysis due to severe blunt chest trauma. J Thorac Dis. 2014;6(12):E255-8. https://doi.org/10.3978/j.issn.2072-1439.2014.10.22.

43. Skarda D, Henricksen JW, Rollins M. Extracorporeal membrane oxygenation promotes survival in children with trauma related respiratory failure. Pediatr Surg Int. 2012;28(7):711-4. https://doi.org/10.1007/s00383-012-3102-x.

44. Yamada T, Osako T, Sakata H, Kuboyama K, Matsuda K, Okamoto A, Nakao A Kotani J. Successful treatment of pulmonary contusion following chest trauma using poly-2-methoxyethyl acrylate, a biocompatible polymer surface coating for extracorporeal membrane oxygenation. Acute Med Surg. 2014;1(2):105-8. https://doi.org/10.1002/ams2.11.

45. Firstenberg MS, Nelson K, Abel E, McGregor J, Eiferman D. Extracorporeal membrane oxygenation for complex multiorgan system trauma. Case Rep Surg. 2012:2012897184, 10.1155/2012/897184.

46. Ballouhey Q, Fesseau R, Benouaich V, Léobon B. Benefits of extracorporeal membrane oxygenation for major blunt tracheobronchial trauma in the paediatric age group. Eur J Cardiothorac Surg. 2013;43(4):864-5. https://doi. org/10.1093/ejcts/ezs607.

47. Campione A, Agostini M, Portolan M, Alloisio A, Fino C, Vassallo G. Extracorporeal membrane oxygenation in respiratory failure for pulmonary contusion and bronchial disruption after trauma. J Thorac Cardiovasc Surg. 2007;133(6):1673-4. https://doi.org/10.1016/j.jtcvs.2007.02.011.

48. Issa N, Napolitano LM. Aeromonas pneumonia in a trauma patient requiring extracorporeal membrane oxygenation for severe acute respiratory distress 
syndrome: case report and literature review. Surg Infect (Larchmt). 2011; 12(3):241-5. https://doi.org/10.1089/sur.2010.037.

49. Rosenthal A, McKenney M, Sanchez R, Lee S, Carrillo EH. Extracorporeal membrane oxygenation for severe hypoxemia after trauma pneumonectomy. Am Surg. 2009;75(12):1258-60.

50. Tunney R, Scott J, Rudralingam V, Liong S, Athwal VS. Secondary sclerosing cholangitis following extracorporeal membrane oxygenation for acute respiratory distress in polytrauma. Clin Case Rep. 2018;6(9):1849-53. https:// doi.org/10.1002/ccr3.1660.

51. Chauhan A, Babovic N, Moraca RJ, Altman DT. Use of extracorporeal membrane oxygenation to stabilize a polytrauma patient during intramedullary nailing of a femoral fracture: a case report. JBJS Case Connect. 2014;4(4):e112. https://doi.org/10.2106/JBJS.CC.N.00029.

52. Bassi E, Azevedo LC, Costa EL, Maciel AT, Vasconcelos E, Ferreira CB, Malbouisson LM, Park M. Hemodynamic and respiratory support using venoarterial extracorporeal membrane oxygenation (ECMO) in a polytrauma patient. Rev Bras Ter Intensiva. 2011

53. Filippini S, Desebbe O, Gamondes D, Henaine R. Synergy between stents and extracorporeal membrane oxygenation in multitrauma patients with inferior vena cava injury. Eur J Cardiothorac Surg. 2013;44(6):1140-2. https:// doi.org/10.1093/ejcts/ezt203.

54. Wen PH, Chan W, Chen YC, Chen YL, Chan CP, Lin PY. Non-heparinized ECMO serves a rescue method in a multitrauma patient combining pulmonary contusion and nonoperative internal bleeding: a case report and literature review. World J Emerg Surg. 2015;10:15. https://doi.org/10.1186/ s13017-015-0006-9.

55. Madershahian N, Wittwer T, Strauch J, Franke UFW, Wippermann J, Kaluza $\mathrm{M}$, Wahlers T. Application of ECMO in multitrauma patients with ARDS as rescue therapy. J Card Surg. 2007;22(3):180-4. https://doi.org/10.1111/j.15408191.2007.00381.x.

56. Lee SK, Gongora E, O'Donnell S, Carrillo EH, Sanchez R, Kiffin C, Davare DL, Rosenthal AA. Intraoperative rescue extracorporeal membrane oxygenation and damage control during repair of a traumatic aortic injury. J Surg Case Rep. 2017:(2):1-3. https://doi.org/10.1093/jscr/rix022.

57. Biscotti M, Gannon WD, Abrams D, Agerstrand C, Claassen J, Brodie D, Bacchetta M. Extracorporeal membrane oxygenation use in patients with traumatic brain injury. Perfusion. 2015;30(5):407-9. https://doi.org/10.1177/ 0267659114554327.

58. Lee OJ, Cho YH, Hwang J, Yoon I, Kim YH, Cho J. Long-term extracorporeal membrane oxygenation after severe blunt traumatic lung injury in a child. Acute Crit Care. 2019;34(3):223-7. https://doi.org/10. 4266/acc.2016.00472.

59. Messing JA, Agnihothri RV, Dusen RV, Najam F, Dunne JR, Honig JR, Sarani B. Prolonged use of extracorporeal membrane oxygenation as a rescue modality following traumatic brain injury. ASAIO J. 2014;60(5):597-9. https:/ doi.org/10.1097/MAT.0000000000000103.

60. Voelckel W, Wenzel V, Rieger M, Antretter H, Padosch S, Schobersberger W. Temporary extracorporeal membrane oxygenation in the treatment of acute traumatic lung injury. Can J Anaesth. 1998;45(11):1097-102. https:// doi.org/10.1007/BF03012399.

61. Yen TS, Liau CC, Chen YS, Chao A. Extracorporeal membrane oxygenation resuscitation for traumatic brain injury after decompressive craniotomy. Clin Neurol Neurosurg. 2008;110(3):295-7. https://doi.org/10.1016/..clineuro.2007. 10.017 .

62. Muellenbach RM, Kredel M, Kunze E, Kranke P, Kuestermann J, Brack A, Gorski A, Wunder C, Roewer N, Wurmb T. Prolonged heparin-free extracorporeal membrane oxygenation in multiple injured acute respiratory distress syndrome patients with traumatic brain injury. J Trauma Acute Care Surg. 2012;72(5):1444-7. https://doi.org/10.1097/TA.0b013e31824d68e3.

63. Valette X, Desjouis A, Massetti M, Hanouz IL, Icard P. Successful use of extracorporeal life support after double traumatic tracheobronchial injury in a patient with severe acute asthma. Pulm Med. 2011;2011:936240. https:// doi.org/10.1155/2011/936240.

64. Barreda E, Flecher E, Aubert S, Leprince P. Extracorporeal life support in right ventricular rupture secondary to blast injury. Interact Cardiovasc Thorac Surg. 2007;6(1):87-8. https://doi.org/10.1510/icvts.2006.140814

65. Regel G, Grotz M, Weltner T, Sturm JA, Tscherne H. Pattern of organ failure following severe trauma. World J Surg. 1996 May;20(4):422-9. https://doi. org/10.1007/s002689900067.

66. Haile DT, Schears GJ. Optimal time for initiating extracorporeal membrane oxygenation. Semin Cardiothorac Vasc Anesth. 2009;13(3):146-53.
67. Paden ML, Conrad SA, Rycus PT, Thiagarajan RR, Registry ELSO. Extracorporeal life support organization registry report 2012. ASAIO J. 2013; 59(3):202-10. https://doi.org/10.1097/MAT.0b013e3182904a52.

68. Arlt M, Philipp A, Voelkel S, Rupprecht L, Mueller T, Hilker M, Graf BM, Schmid C. Extracorporeal membrane oxygenation in severe trauma patients with bleeding shock. Resuscitation. 2010;81(7):804-9. https://doi.org/10. 1016/j.resuscitation.2010.02.020

\section{Publisher's Note}

Springer Nature remains neutral with regard to jurisdictional claims in published maps and institutional affiliations.
Ready to submit your research? Choose BMC and benefit from:

- fast, convenient online submission

- thorough peer review by experienced researchers in your field

- rapid publication on acceptance

- support for research data, including large and complex data types

- gold Open Access which fosters wider collaboration and increased citations

- maximum visibility for your research: over $100 \mathrm{M}$ website views per year

At $\mathrm{BMC}$, research is always in progress.

Learn more biomedcentral.com/submissions 